Int. J. Electrochem. Sci., 14 (2019) 10289 - 10305

\title{
Preparation of Ginger Straw based Porous Carbon using One- step Pyrolysis Process as Electrode Material for Supercapacitor
}

\author{
Jinxiao Li, Jiamin Wang, Kuihua Han*, Jianhui Qi, Ming Li, Zhaocai Teng, Meimei Wang \\ School of Energy and Power Engineering, Shandong University, 250061 Jinan, PR China \\ *E-mail: hankh@163.com
}

doi: $10.20964 / 2019.11 .29$

Received: 17 June 2019 / Accepted: 20 August 2019 / Published: 7 October 2019

Conventional preparation for porous carbon is expensive, complex, leading to a low yield. In this study, a one-step pyrolysis synthesis method without any chemical additive is designed based on the natural tubular structures and components (rich in potassium) of the ginger straw. The physicochemical and electrochemical performance of the product are studied, and the synthesis mechanism is discussed. Based on the excellent hierarchical porous structure, the specific capacitance can reach $274 \mathrm{~F} \mathrm{~g}^{-1}(38.1 \mu \mathrm{F} \mathrm{cm}$ $\left.{ }^{1}\right) @ 0.1 \mathrm{~A} \mathrm{~g}^{-1}$, and the specific capacitance can retain $88 \%$ after 6000 cycles at the current density of 5 $\mathrm{A} \mathrm{g}^{-1}$. The maximum energy density and power density can be $34.06 \mathrm{~W} \mathrm{~h} \mathrm{~kg}^{-1}$ and $4.35 \mathrm{~kW} \mathrm{~kg}^{-1}$. This study provides a new perspective for designing preparation method based on the component and structure characteristics of the raw material, and provide a new perspective on the treatment of ginger straw waste.

Keywords: synthesis method; porous carbon; supercapacitor; electrochemical performance; biomass

\section{FULL TEXT}

(C) 2019 The Authors. Published by ESG (www.electrochemsci.org). This article is an open access article distributed under the terms and conditions of the Creative Commons Attribution license (http://creativecommons.org/licenses/by/4.0/). 